\title{
Acolhimento e as Diferentes Visões na Estratégia Saúde da Família
}

\author{
Pereira, Marcelo Lopes; Reis, Ana Paula Alonso; Ribeiro, João Henrique de Morais; \\ Pereira, Marina Cortez; Resck, Zélia Marilda Rodrigues \\ Universidade Federal de Alfenas — marcelo_enfer1@yahoo.com.br
}

Introdução: o acolhimento é uma função que se estende a todos profissionais das unidades de saúde da família (USF). Consiste em promover uma reorganização dos serviços de saúde, abrindo as portas destes para a população, proporcionando uma escuta ativa de seus problemas de saúde, resolvendo os que estão dentro de seu espectro de ações e referenciando os de maior complexidade. Diante da importância atribuída à prática do acolhimento, faz-se importante um melhor conhecimento sobre como este é visto pelos usuários e profissionais das USF, e como ele pode contribuir para que haja o rompimento do atual modelo de cuidado à saúde. Objetivo: Integrar e discutir o conhecimento produzido sobre o acolhimento nas Unidades de Saúde da Família. Métodos: Trata-se de uma revisão integrativa. a busca de artigos foi realizada na Biblioteca Virtual de Saúde BVS, resultando em 13 estudos que responderam a seguinte questão norteadora: como o acolhimento vem sendo praticado e visualizado nas ESF? como critérios de inclusão dos artigos estabeleceram-se: artigos disponíveis na íntegra; publicados nos últimos seis anos; nos idiomas português, inglês e espanhol; indexados nas bases de dados mencionadas; que versassem acerca do acolhimento nas Estratégias de Saúde da Família. a interpretação e análise dos dados obtidos pela pergunta norteadora aplicou-se o método de Análise de Conteúdo, que propiciou o agrupamento do conteúdo em categorias temáticas, a saber: a visão do acolhimento pelo profissional de saúde; o olhar do usuário sobre o acolhimento e, por fim, o poder de transformar o modelo hegemônico organizacional. Resultados e discussão: na visão do profissional de saúde, acolhimento é entendido como triagem humanizada e necessária para promover mudanças no serviço de saúde. Faz com que os profissionais entendam os reais problemas da população, possam dar uma maior atenção nos casos necessários e melhorem a dinâmica do atendimento, partilhando os problemas com os demais profissionais e agilizando o atendimento. para os usuários, Os usuários relataram que ao realizarem o acolhimento, os profissionais devem fazer uso do diálogo, da atenção, da paciência e da compreensão. Reforçaram que com a utilização do acolhimento o atendimento se tornou mais ágil, estes se sentiram mais valorizados, mais seguros para falar sobre seus problemas e tiveram sua autoestima aumentada. em relação à transformação do modelo hegemônico, a prática do acolhimento é um processo imprescindível para a construção do cuidado integral na USF. Conclusão: o acolhimento é um exercício potencial de reorganizar o atendimento aos usuários da USF proporcionando uma atenção humanizada, qualificada, livre de danos e de responsabilização pelas necessidades dos cidadãos.

Pereira, Marcelo Lopes; Reis, Ana Paula Alonso; Ribeiro, João Henrique de Morais; Pereira, Marina Cortez; Resck, Zélia Marilda Rodrigues. Acolhimento e As Diferentes Visões na Estratégia Saúde da Família. In: Anais do Congresso Internacional de Humanidades \& Humanização em Saúde [= Blucher Medical Proceedings, num.2, vol.1]. São Paulo: Editora Blucher, 2014. ISSN 2357-7282

DOI 10.5151/medpro-cihhs-10550 